\title{
Bulletin bibliographique
}

\section{(2) OpenEdition}

1 Journals

Édition électronique

URL : https://journals.openedition.org/philosant/4062

DOI : 10.4000/philosant.4062

ISSN : 2648-2789

Éditeur

Éditions Vrin

\section{Édition imprimée}

Date de publication : 31 octobre 2020

Pagination : 306-307

ISBN : 978-2-7116-2977-0

ISSN : 1634-4561

\section{Référence électronique}

«Bulletin bibliographique », Philosophie antique [En ligne], 20 | 2020, mis en ligne le 15 novembre 2020, consulté le 07 décembre 2022. URL : http://journals.openedition.org/philosant/4062 ; DOI : https:// doi.org/10.4000/philosant.4062

\section{(c) (i) (9)}

Creative Commons - Attribution - Pas d'Utilisation Commerciale - Pas de Modification 4.0 International - CC BY-NC-ND 4.0

https://creativecommons.org/licenses/by-nc-nd/4.0/ 


\section{Bulletin Bibliographique}

\section{Éditions, traductions et commentaires}

- Alcméon de Crotone, Fragments, éd. par Magali Année, Paris, Vrin (Bibliothèque des Textes Philosophiques), 2020, 188 p., ISBN 978-2-7116-2944-2.

- Ammonius, Interpretation of Porphyry's Introduction to Aristotle's Five Terms, trans. M. Chase, London; New York (N.Y.), Bloomsbury academic (Ancient Commentators on Aristotle), 2019, 200 p., ISBN 9781350089228.

- Michael of Ephesus, On Aristotle's Nicomachean Ethics 10, tr. J. Wilberding \& J. Trompeter ; Themistius, On Virtue, tr. A. Rigolio, London, Bloomsbury academic (Ancient Commentators on Aristotle), 2018, 280 p., ISBN 9781350085077.

- Philoponus, On Aristotle Categories 6-15, tr. M. Share, London ; New York (N.Y.) Bloomsbury academic (Ancient Commentators on Aristotle), 2019, 232 p., ISBN 9781350112674 .

\section{Études}

- Kelly Arenson, Health and Hedonism in Plato and Epicurus, London ; New York, Bloomsbury, 2019, x-217 p., ISBN 9781350080256.

- Jed W. Atkins, Roman Political Thought, Cambridge, Cambridge University Press, 2018, 256 p., ISBN : 9781316227404

https://doi.org/10.1017/9781316227404 .

- Orazio Cappello, The School of Doubt: Skepticism, History and Politics in Cicero's 'Academica', Leiden, Brill (Brill Studies in Scepticism, 1), 2019, xiv-382 p., ISBN : 978-9004-38987-8.

https://doi.org/10.1163/9789004389878

- Pierre Caye, Comme un nouvel atlas: d'un état meilleur que la puissance, Paris, Les Belles lettres (L'Âne d'or, 66), 2017, 240 p., ISBN : 9782251447322.

- Sylvain Delcomminette, Aristote et la nécessité, Paris,Vrin (Tradition de la pensée classique), 2018, 648 p., ISBN : 978-2-7116-2736-3.

- Françoise Frazier, Quelques aspects du platonisme de Plutarque : philosopher en commun, tourner sa pensée vers Dieu, édité par Lautaro Roig Lanzillotta, Leiden, Brill (Brill Plutarch's Studies, 4), 2020, xvi-548 p., ISBN: 978-90-04-41598-0.

https://doi.org/10.1163/9789004415980

- Pierre Ponchon, Thucydide philosophe : la raison tragique dans l'histoire, Grenoble, Éditions Jérôme Millon (Horos), 2016, 451 p., ISBN : 978-2-84137-329-1.

- Marwan Rashed, La jeune fille et la sphère : études sur Empédocle, Paris, PUPS, (Philosophies), 2017, 298 p., ISBN : 979-10-231-0571-1.

\section{Recueils}

- Katerina Ierodiakonou, Paul Kalligas, et Vassilis Karasmanis (éd.), Aristotle’s Physics Alpha: Symposium Aristotelicum, Symposia Aristotelica, Oxford, New York, Oxford University Press, 2019, viii-377 p., ISBN 9780198830993. 
- Maria Michela Sassi (a cura di), La zoologia di Aristotele e la sua ricezione dall'età ellenistica e romana alle culture medievali : atti della X "Settimana di formazione" del Centro GrAL, Pisa, 18-20 novembre 2015, con Elisa Coda e Giuseppe Feola, Pisa, Pisa University Press (Greco, arabo, latino. Studi, 6), 2018, 315 p., ISBN 9788867418350.

- Anne-Isabelle Bouton-Touboulic et Carlos Lévy (éd.), Scepticisme et religion: constantes et évolutions, de la philosophie hellénistique à la philosophie médiévale, Turnhout, Brepols, (Monothéismes et philosophie, 21), 2016, 300 p., ISBN 9782503565453.

- Katja Maria Vogt et Justin Vlasits (éd.), Epistemology After Sextus Empiricus, Oxford, New York, Oxford University Press, 2020, 368 p., ISBN 9780190946302.

https://doi.org/10.1093/oso/9780190946302.001.0001

- Peter Burian, Jenny Strauss Clay, et Gregson Davis (éd.), Euphrosyne : Studies in Ancient Philosophy, History, and Literature, Berlin, Boston, De Gruyter, 2020 (Beiträge zur Altertumskunde, 370), X-328 p., ISBN 978-3-11-059765-3.

https://doi.org/10.1515/9783110605938 